\title{
PILIHAN TEKNOLOGI SALURAN SIMPANG BESI TUA- PANGLIMA KAOM PADA SISTEM DRAINASE WILAYAH IV KOTA LHOKSEUMAWE
}

\author{
Wesli \\ Dosen Jurusan Teknik Sipil, Universitas Malikussaleh \\ email: ir_wesli@yahoo.co.id
}

\begin{abstract}
Abstrak
Kota Lhokseumawe mempunyai dataran yang cenderung landai dengan kemiringan lereng 0,0002 hal ini menyebabkan pengaliran air cenderung lamban (kecepatan rendah) sehingga pada daerah layanan yaitu sekitar desa Ujong Blang sering terjadi banjir setiap tahunnya bahkan pada hampir setiap terjadinya hujan. Untuk mengatasi hal tersebut perlu dilakukan penelitian untuk menentukan pilihan teknologi yang tepat agar kejadian banjir dapat direduksi. Analisis hidrologi dilakukan berdasarkan data hujan series selama 10 tahun dengan uji kecocokan data menggunakan metode distribusi Smirnov-Kolmogorov. Analisa hidrolika dilakukan untuk design penampang saluran dan potongan memanjang direncanakan dengan cara luncuran karena kemiringan pada lokasi penelitian cenderung datar, hal ini dilakukan untuk mendapatkan kemiringan yang cukup dalam upaya meningkatkan kecepatan aliran. Hasil penelitian memnggambarkan bahwa melalui pembagian zoning (pembagian zona) menjadi 3 bagian yaitu pada STA P1 sampai P8 disebut dengan Section III, dari STA P8 sampai P 16 disebut dengan Section II, dan dari STA P16 sampai P 26 disebut Section I dibuat luncuran dasar saluran dengan kemiringan 0,001. Dan permukaan saluran dinaikkan setinggi $20 \mathrm{~cm}$ dari dasar saluran sehingga pada pada zoning yang satu dengan zoning yang lain terjadi perbedaan kedalaman dasar saluran sebesar 20-35 cm. Dengan adanya perbedaan tinggi ini nantinya perlu pemeliharaan secara berkala agar fungsi saluran tetap maksimal.
\end{abstract}

Kata Kunci : Pilihan Teknologi, Tampang ekonomis

\section{Pendahuluan}

Kota Lhokseumawe mempunyai luasan sebesar $181,10 \mathrm{~km}^{2}$ meliputi 4 kecamatan yaitu kecamatan Muara Satu, kecamatan Muara dua, kecamatan Banda Sakti dan kecamatan dan kecamatan Blang Mangat. Saluran Simpang Besi TuaPanglima Kaom terletak di kecamatan Banda Sakti dengan panjang $1350 \mathrm{~m}$ dan luas daerah layanan $0,65 \mathrm{~km}^{2}$ mempunyai kemiringan lereng 0,0002 . Pada daerah layanan yaitu sekitar desa Ujong Blang sering terjadi banjir setiap tahunnya bahkan pada hampir setiap terjadinya hujan. Pengaliran air di daerah layanan bermuara ke Sistem Tando IV yang berada di desa Ulee Jalan sejarak 3000 m dari hulu saluran yang ditinjau. Pada penelitian ini saluran dibagi dalam 27 STA dengan jarak masing-masing STA sebesar $50 \mathrm{~m}$ dengan tujuan penyederhanaan analisis sehingga penentuan pilihan teknologi pada setiap STA mempunyai akurasi yang lebih tepat di mana STA $\mathrm{P}_{0}$ berada pada bagian hulu dan STA $\mathrm{P}_{27}$ berada pada bagian hilir saluran. Layout pembagian zona pada lokasi penelitian seperti diperlihatkan pada Gambar 1 
Permasalahan umum pada sistem drainase kota Lhokseumawe adalah kelandaian lereng yang sangat kecil berkisar dari 0,0001 sampai 0,00025 dan ketinggian dataran dari muka air laut hanya 1,75 m sehingga kecepatan aliran menjadi rendah. Selain itu banyaknya sampah pada saluran juga merupakan faktor penyebab terjadinya banjir. Pada penelitian ini dilakukan pilihan teknologi dengan membuat luncuran-luncuran pada STA tertentu dengan tujuan memperbesar kelandaian pada saluran yang diharapkan dapat meninggikan kecepatan aliran khususnya pada saat hujan agar limpasan permukaan dapat direduksi sekecil mungkin.

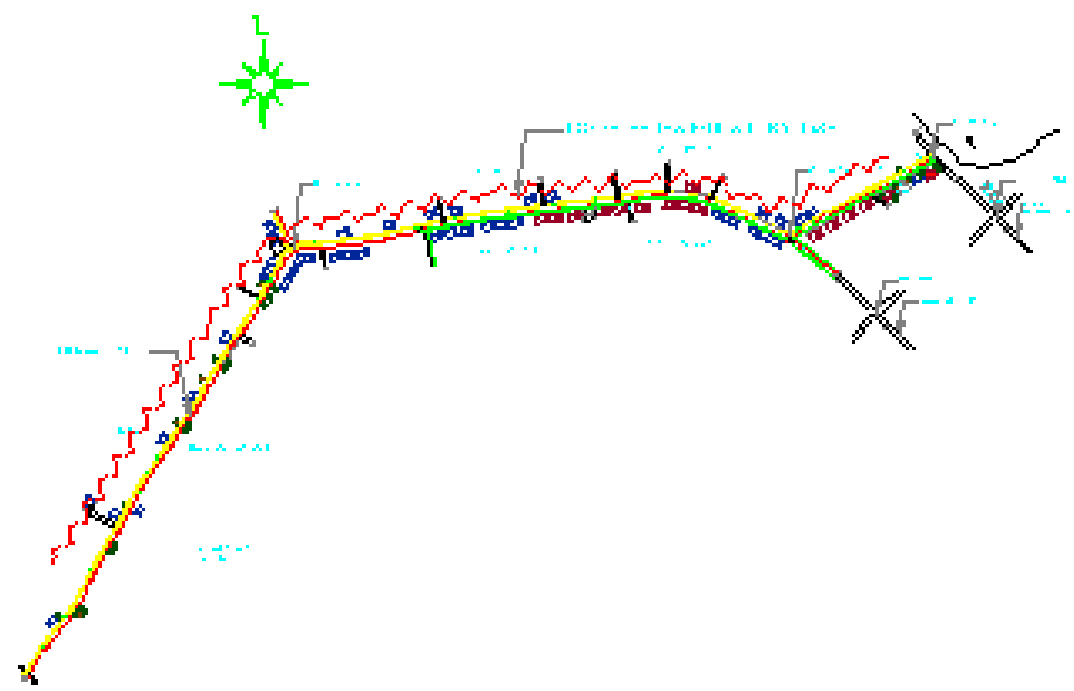

Gambar 1 Layout Lokasi Penelitian

\section{Tinjauan Kepustakaan}

\subsection{Analisis Hidrologi}

Analisis hidrologi bertujuan untuk menentukan debit yang dilakukan melalui analisis hujan rencana, intensitas hujan dan debit aliran. Menurut Wesli (2008), hujan rencana yang dimaksud adalah hujan harian maksimum yang akan digunakan untuk menghitung intensitas hujan, kemudian intensitas hujan ini digunakan untuk mengestimasi debit rencana. Hujan rencana dapat dihitung secara statistik berdasarkan data curah hujan terdahulu.

\subsection{Periode ulang (return period)}

Menurut Asdak (1995), periode ulang adalah periode waktu rata-rata yang diharapkan terjadi antara dua kejadian yang berurutan. Periode ulang (Tr) biasanya diprakirakan dari data curah hujan serial tahunan dengan bentuk persamaan:

$$
\operatorname{Tr}=\frac{n+1}{m}
$$

di mana:

$\operatorname{Tr}=$ Periode ulang (tahun)

$\mathrm{n} \quad=$ Periode data debit yang tercatat

$\mathrm{m}$ = Jumlah kejadian, apabila disusun mulai yang terbesar sampai yang terkecil 
Hujan rencana dapat dihitung secara statistik berdasarkan data curah hujan terdahulu dengan menggunakan rumus sebagai berikut :

$$
\begin{aligned}
& R_{r}=\bar{R}+K \cdot S_{d} \\
& \bar{R}=\frac{\sum_{i=1}^{n} R_{i}}{n} \\
& S_{d}=\sqrt{\frac{\sum_{i=1}^{n}\left(R_{i}-\bar{R}\right)^{2}}{n-1}}
\end{aligned}
$$

di mana :

$R_{r}=$ Hujan rencana periode ulang $\mathrm{T}$ tahun $(\mathrm{mm})$

$\bar{R}=$ Hujan harian tahunan maksimum rata-rata $(\mathrm{mm})$

$K=$ Faktor frekwensi untuk periode ulang $\mathrm{T}$ tahun sesuai dengan tipe sebaran data hujan

$S_{d}=$ Standar deviasi

$R_{i}=$ Hujan harian maksimum tahun ke i

\subsection{Uji kecocokan distribusi Smirnov-Kolmogorov}

Menurut Wesli (2008), uji kecocokan distribusi Smirnov-Kolmogorov sering juga disebut uji kecocokan no parametrik (non parametric test), karena pengujiannya tidak menggunakan fungsi distribusi tertentu. Prosedur untuk uji Smirnov-kolmogorov ini dilakukan dengan cara sebagai berikut:

a. Urutkan data dari besar ke kecil dan tentukan peluang dan masing-masing data tersebut dengan menggunakan rumus:

$$
p=\frac{m}{n+1} \times 100 \%
$$

di mana:

$$
\begin{aligned}
& \mathrm{P}=\text { Probabilitas }(\%) \\
& \mathrm{m}=\text { Nomor urut data setelah diurut dari besar ke kecil } \\
& \mathrm{n}=\text { Jumlah tahun data }
\end{aligned}
$$

b. Tentukan peluang teoritis untuk masing-masing data tersebut berdasarkan persamaan distribusinya:

c.

$$
\mathrm{P}^{\prime}=\frac{1}{T}
$$

d. Dari kedua nilai peluang tersebut, tentukan selisih terbesar antara peluang pengamatan dengan peluang teoritis:

$$
\mathrm{D}=\text { maksimum }\left[P\left(Q_{\text {maks }}\right)-P^{\prime}\left(Q_{\text {maks }}\right)\right]
$$

e. Berdasarkan tabel untuk nilai kritis Smirnov-Kolmogorov ditentukan harga Do. 
f. Apabila D lebih kecil dari Do maka distribusi yang digunakan untuk menentukan debit rencana dapat diterima, sebaliknya jika harga D lebih besar dari Do, maka distribusi yang digunakan untuk menentukan debit rencana tidak diterima.

\subsection{Intensitas Hujan Maksimum Periode Ulang T Tahun}

Menurut Sosrodarsono (1997) intensitas hujan ialah ketinggian hujan yang terjadi pada suatu kurun waktu air hujan terkonsentrasi. Biasanya intensitas hujan dihubungkan dengan durasi hujan jangka pendek misalnya 5 menit, 30 menit, 60 menit dan jam-jaman. Data curah hujan jangka pendek ini hanya dapat diperoleh dengan menggunakan alat pencatat hujan otomatis. Di Indonesia alat ini sangat sedikit dan jarang, yang banyak digunakan adalah alat pencatat hujan biasa yang mengukur hujan 24 jam atau disebut hujan harian. Menurut Soemarto (1993) apabila yang tersedia hanya data hujan harian ini maka intensitas hujan dapat diestimasi dengan menggunakan rumus Mononobe seperti berikut:

$$
I_{T}=\frac{R_{24 T}}{24}\left(\frac{24}{T_{c}}\right)^{2 / 3}
$$

di mana:

$I_{T} \quad=$ Intensitas hujan maksimum periode ulang $\mathrm{T}$ tahun $(\mathrm{mm} / \mathrm{jam})$

$R_{24 T}=$ Curah hujan harian maksimum dalam 24 jam pada periode ulang $\mathrm{T}$ tahun (mm)

$T_{\mathrm{c}} \quad=$ Waktu konsentrasi (jam)

Besarnya waktu konsentrasi (Tc) ditentukan oleh panjang saluran yang dilalui aliran dan kemiringan saluran, seperti ditunjukkan oleh persamaan:

$$
T_{c}=0.00013 \frac{L^{0.77}}{S^{0.385}}
$$

di mana:

$T c=$ waktu konsentrasi (jam);

$L=$ Panjang jarak dari tempat terjauh didaerah aliran sampai tempat pengamatan banjir, di ukur menurut jalannya sungai $(\mathrm{km})$

$S=$ Perbandingan dari selisih tinggi antara tempat terjauh dan tempat pengamatan, diperkirakan sama dengan kemiringan rata-rata dari daerah aliran.

\subsection{Debit Aliran}

Menurut Wesli (2008), ada banyak rumus rasional yang dibuat secara empiris yang dapat menjelaskan hubungan antara hujan dengan limpasannya diantaranya adalah:

$$
Q=0,278 . C . I \cdot A
$$


di mana:

$$
\begin{array}{ll}
\mathrm{Q} & =\text { Debit }\left(\mathrm{m}^{3} / \mathrm{det}\right) \\
\mathrm{C} & =\text { Koefisien aliran } \\
\mathrm{I} & =\text { Intensitas hujan selama waktu konsentrasi }(\mathrm{mm} / \mathrm{jam}) \\
\mathrm{A} & =\text { Luas daerah aliran }\left(\mathrm{km}^{2}\right)
\end{array}
$$

\subsection{Penampang Melintang}

Menurut Triatmodjo B (1995) bahwa kecepatan akan bertmbah dengan jarijari hidraulis sehingga untuk luas tampang basah tertentu debit akan maksimum apabila nilai $\mathrm{R}=\mathrm{A} / \mathrm{P}$ maksimum atau keliling basah minimum.

Untuk menentukan penampang saluran maka dapat digunakan persamaan debit saluran:

$$
Q=A . V
$$

Sementara untuk menentukan kecepatan aliran (V) dapat digunakan persamaan Manning:

$$
V=\frac{1}{n} \cdot R^{2 / 3} I^{1 / 2}
$$

Sehingga luas penampang saluran menjadi:

$$
A=\frac{Q}{\frac{1}{n} R^{2 / 3} I^{1 / 2}}
$$

di mana:

$$
\begin{aligned}
\mathrm{Q} & =\text { Debit }\left(\mathrm{m}^{3} / \mathrm{det}\right) \\
\mathrm{A} & =\text { Koefisien aliran } \\
\mathrm{V} & =\text { Intensitas hujan selama waktu konsentrasi }(\mathrm{mm} / \mathrm{jam}) \\
\mathrm{n} & =\text { Luas daerah aliran }\left(\mathrm{km}^{2}\right) \\
\mathrm{R} & =\text { Debit }\left(\mathrm{m}^{3} / \mathrm{det}\right) \\
\mathrm{I} & =\text { Koefisien aliran }
\end{aligned}
$$

\section{Metode Penelitian}

Penelitian dilakukan melalui analisis hidrologi berdasarkan data hujan series selama 10 tahun untuk mendapatkan besaran debit yang akan dialirkan. Untuk memastikan bahwa sebaran data tersebar dalam distribusi normal maka dilakukan uji kecocokan data dengan metode distribusi Smirnov-Kolmogorov sering juga disebut uji kecocokan no parametrik (non parametric test). Metode Smirnov Kolmogorov membandingkan nilai D0 yang diperoleh berdasarkan tabel nilai kritis Smirnov-Kolmogorov dengan nilai D yang diperoleh dari perhitingan. Apabila nilai D lebih kecil dari Do maka distribusi yang digunakan untuk menentukan debit rencana dapat diterima, sebaliknya jika harga D lebih besar dari 
Do, maka distribusi yang digunakan untuk menentukan debit rencana tidak dapat diterima.

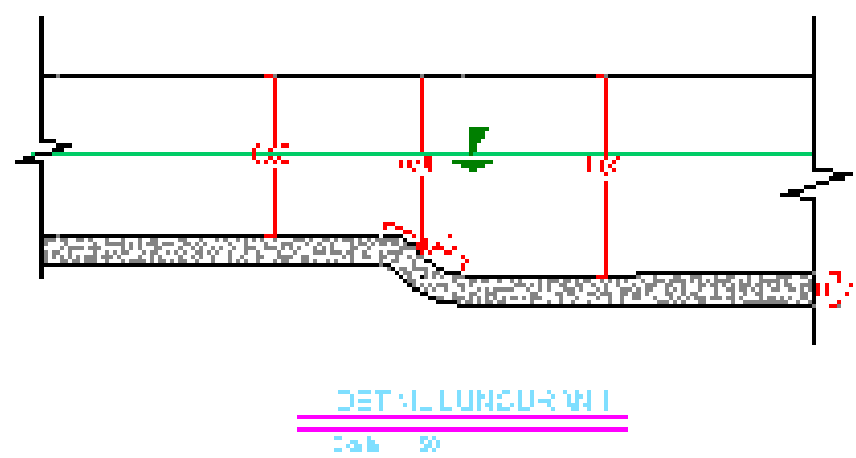

Gambar 2 Luncuran Saluran Pada Arah Memanjang Saluran

Analisa hidrolika dilakukan untuk design penampang saluran dan potongan memanjang direncanakan dengan cara luncuran karena kemiringan pada lokasi penelitian cenderung datar, hal ini dilakukan untuk mendapatkan kemiringan yang cukup dalam upaya meningkatkan kecepatan aliran seperti diperlihatkan pada Gambar 2.

\section{$4 \quad$ Analisis dan Pembahasan}

\subsection{Intensitas Hujan Periode Ulang}

Data hujan selama 10 tahun tahun sejak tahun 2000 sampai dengan tahun 2009 diperoleh dari Badan Meteorologi dan Geofisika Stasion Meteorologi Lhokseumawe. Pengolahan data hujan seperti diperlihatkan pada Tabel 1

Tabel 1 Data Hujan Selama 10 Tahun Dari Tahun 2000 - 2009

\begin{tabular}{|c|r|r|r|r|}
\hline TAHUN & \multicolumn{1}{|c|}{$\mathbf{R}$} & R rerata & R - R rerata & ${\text { (R - Rrerata })^{\mathbf{2}}}^{1}$ \\
\hline 2000 & 167,4 & 116,7 & 50,7 & $2.571,4$ \\
\hline 2001 & 145,3 & 116,7 & 28,6 & 819,4 \\
\hline 2002 & 72,3 & 116,7 & $(44,4)$ & $1.969,1$ \\
\hline 2003 & 115,6 & 116,7 & $(1,1)$ & 1,2 \\
\hline 2004 & 99,9 & 116,7 & $(16,8)$ & 281,9 \\
\hline 2005 & 130,5 & 116,7 & 13,8 & 190,5 \\
\hline 2006 & 91,5 & 116,7 & $(25,2)$ & 635,4 \\
\hline 2007 & 117,1 & 116,7 & 0,4 & 0,1 \\
\hline 2008 & 102,4 & 116,7 & $(14,3)$ & 205,4 \\
\hline 2009 & 125,0 & 116,7 & 8,3 & 68,5 \\
\hline Jumlah & $\mathbf{1 . 1 6 7 , 1}$ & & & $\mathbf{6 . 7 4 3 , 0}$ \\
\hline Rerata & $\mathbf{1 1 6 , 7}$ & & & \\
\hline
\end{tabular}

Sebaran hujan dari tahun ke tahun selama 10 tahun seperti diperlihatkan pada Gambar 3. 


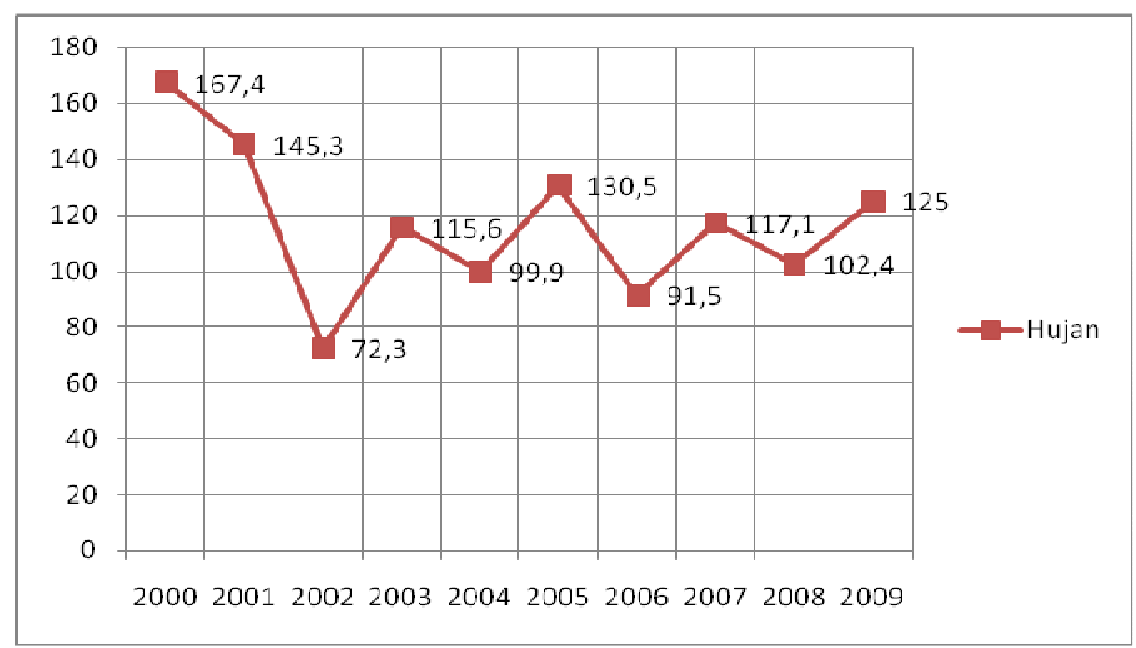

Gambar 3 Sebaran hujan selama 10 tahun

Dari Tabel 1 maka dapat dihitung besarnya standar deviasi menggunakan persamaan (4). Besarnya standar deviasi adalah 27,4. Dari hasil standar deviasi maka dapat dihitung hujan periode ulang menggunakan persamaan (2) seperti diperlihatkan pada Tabel 2.

Tabel 2 Rekapitulasi Hujan Harian dan Intensitas Hujan

\begin{tabular}{|c|c|c|c|c|c|}
\hline $\begin{array}{c}\text { PERIODE } \\
\text { ULANG }\end{array}$ & $\boldsymbol{Y}_{\boldsymbol{T R}}$ & $\boldsymbol{K}$ & $\boldsymbol{S}_{\boldsymbol{d}}$ & $\boldsymbol{R}_{\mathbf{2 4}}$ & $\boldsymbol{I}_{\boldsymbol{T}}$ \\
\hline 2 & 0,37 & $-0,13$ & 27,44 & 113,14 & 40,31 \\
\hline 5 & 1.50 & 1,06 & 27,44 & 145,744 & 51,92 \\
\hline 10 & 2.25 & 1,85 & 27,44 & 167,39 & 59,63 \\
\hline
\end{tabular}

\subsection{Uji Kecocokan Distribusi Dengan Uji Smirnov Kolmogorov}

Uji Smirnov Kolmogorov dilakukan untuk melihat kecocokan distribusi data apakah dapat diterima atau ditolak. Untuk itu dilakukan analisis Peluang seperti diperlihatkan pada Tabel 3

Tabel 3 Uji Kecocokan Smirnov Kosmogorov

\begin{tabular}{|c|c|c|c|c|c|}
\hline $\mathbf{m}$ & $\mathbf{R}$ & $\mathbf{P}=\mathbf{m} /(\mathbf{n}+\mathbf{1})$ & $\mathbf{T}$ & $\mathbf{P}^{\prime}=\mathbf{1} / \mathbf{T}$ & $\mathbf{D}=\left|\mathbf{P}-\mathbf{P}^{\prime}\right|$ \\
\hline 1 & 167,4 & 0,09 & 11,08 & 0,09 & $(0,00)$ \\
\hline 2 & 145,3 & 0,18 & 5,45 & 0,18 & 0,00 \\
\hline 3 & 130,5 & 0,27 & 3,48 & 0,29 & 0,01 \\
\hline 4 & 125,0 & 0,36 & 2,97 & 0,34 & $(0,03)$ \\
\hline 5 & 117,1 & 0,45 & 2,40 & 0,42 & $(0,04)$ \\
\hline 6 & 115,6 & 0,55 & 2,31 & 0,43 & $(0,11)$ \\
\hline 7 & 102,4 & 0,64 & 1,69 & 0,59 & $(0,05)$ \\
\hline 8 & 99,9 & 0,73 & 1,61 & 0,62 & $(0,10)$ \\
\hline 9 & 91,5 & 0,82 & 1,37 & 0,73 & $(0,09)$ \\
\hline 10 & 72,3 & 0,91 & 1,09 & 0,92 & 0,01 \\
\hline
\end{tabular}


Tabel 4 Nilai Kritis Do untuk Uji Smirnov-Kolmogorov

\begin{tabular}{|l|l|l|l|l|}
\hline \multirow{2}{*}{$\mathrm{N}$} & \multicolumn{2}{|c|}{$\alpha$} & 0,05 & 0,01 \\
\cline { 2 - 5 } & 0,20 & 0,51 & 0,56 & 0,67 \\
\hline 5 & 0,45 & 0,37 & 0,41 & 0,49 \\
10 & 0,32 & 0,30 & 0,34 & 0,40 \\
15 & 0,27 & 0,26 & 0,29 & 0,36 \\
20 & 0,23 & 0,24 & 0,27 & 0,32 \\
25 & 0,21 & 0,22 & 0,24 & 0,29 \\
30 & 0,19 & 0,20 & 0,23 & 0,27 \\
35 & 0,18 & 0,19 & 0,21 & 0,25 \\
40 & 0,17 & 0,18 & 0,20 & 0,24 \\
45 & 0,16 & 0,17 & 0,19 & 0,23 \\
50 & 0,15 & $1,22 / \mathrm{n}^{0,5}$ & $1,36 / \mathrm{n}^{0,5}$ & $1,63 / \mathrm{n}^{0,5}$ \\
\hline$>50$ & $1,07 / \mathrm{n}^{0,5}$ & \multicolumn{3}{|c|}{ Sumber Soewarno $(1995)$} \\
\hline
\end{tabular}

Tabel 3 dapat diketahui bahwa nilai Dmax pada $\mathrm{m}=2$ dan $\mathrm{m}=10$ yang besarnya Dmax $=0.01$

Dari Tabel 4 berdasarkan $\mathrm{n}=10$ dengan derajat kepercayaan $\alpha=5 \%$ maka diperoleh nilai Do $=0.41$

Dari sini dapat diketahui bahwa Nilai Dmax < Do maka Distribusi Gumbel Tipe I dapat diterima

\subsection{Debit Maksimum}

Berdasarkan hujan harian dan intensitas hujan periode ulang dapat diperhitungkan debit maksimum yang terjadi seperti diperlihatkan pada Tabel 5

Tabel 5 Perhitungan Debit Maksimum

$\begin{array}{lrl}\text { Luas Daerah Layanan } & 0,65 & \mathrm{~km}^{2} \\ \text { Panjang Saluran } & 1,3 \mathrm{Km}\end{array}$

\begin{tabular}{|c|c|c|c|c|}
\hline $\begin{array}{c}\text { PERIODE } \\
\text { ULANG }\end{array}$ & $\mathbf{R}_{\mathbf{2 4}}$ & $\mathbf{I}_{\mathbf{T}}$ & $\begin{array}{c}\text { Koef. Alir } \\
\text { DAS }(\mathbf{C})\end{array}$ & $\begin{array}{c}\mathbf{Q} \\
\left(\mathbf{m}^{\mathbf{3}} / \mathbf{d e t}\right)\end{array}$ \\
\hline 2 & 113,14 & 40,31 & 0,70 & 5,10 \\
\hline 5 & 145,744 & 51,92 & 0,70 & 6,57 \\
\hline 10 & 167,39 & 59,63 & 0,70 & 7,54 \\
\hline
\end{tabular}

\subsection{Dimensi Saluran}

Debit Rencana diperhitungkan pada periode ulang 5 tahun sebesar 6,57 $\mathrm{m}^{3} /$ det. Berdasarkan debit rencana tersebut maka dilakukan simulasi terhadap dimensi saluran seperti diperlihatkan pada Tabel 6

\section{Tabel 6 Simulasi Dimensi Saluran}

\begin{tabular}{|c|c|c|c|c|c|c|}
\hline $\mathrm{b}$ & $\mathrm{h}$ & $\mathrm{A}$ & $\mathrm{S}$ & $\mathrm{n}$ & $\mathrm{V}$ & $\mathrm{Q}$ \\
\hline 1,1 & 1,2 & 1,32 & 0,001333 & 0,015 & 5,611644 & 7,407371 \\
\hline
\end{tabular}


Dari hasil perhitungan dan simulasi dimensi saluran maka diperoleh dimensi saluran minimal menjadi: Lebar : $110 \mathrm{~cm}$

$$
\text { Tinggi : } 120 \mathrm{~cm}
$$

\section{$5 \quad$ Kesimpulan dan Rekomendasi}

Berdasarkan hasil kajian di atas maka dapat diambil beberapa kesimpulan dan saran sebagai berikut:

\subsection{Kesimpulan}

Dari hasil analisis dimensi saluran dan analisis hujan maka dibuat pilihan teknologi terhadap penanganan drainase Sp Besi Tua-Jalan Panglima Kaom sebagai berikut:

1. Dilakukan pembagian Zoning (pembagian zona) menjadi 3 bagian yaitu pada STA P1 sampai P8 disebut dengan Section III, dari STA P8 sampai P 16 disebut dengan Section II, dan dari STA P16 sampai P 26 disebut Section I

2. Untuk meningkatkan kecepatan aliran pada saat curah hujan tinggi maka dari STA P1 sampai P8 pada section III dibuat luncuran dasar saluran dengan kemiringan 0,001 .

3. Pada Section II dimulai dari STA P8 permukaan saluran dinaikkan setinggi $20 \mathrm{~cm}$ dari dasar saluran akhir section III dan dibuat luncuran dengan kemiringan 0,001 sehingga pada STA P8 terjadi perbedaan kedalaman dasar saluran sebesar $20 \mathrm{~cm}$

4. Pada Section I dimulai dari STA P16 permukaan saluran dinaikkan setinggi $20 \mathrm{~cm}$ dari dasar saluran akhir section II dan dibuat luncuran dengan kemiringan 0,001 sehingga pada STA P16 terjadi perbedaan kedalaman dasar saluran sebesar $20 \mathrm{~cm}$

5. Demikian juga pada STA P26 yaitu akhir dari section I yaitu pertemuan antara saluran Sp Besi Tua-Jalan Panglima Kaom dengan Saluran pembuang akhir terdapat perbedaan kedalaman dasar saluran sebesar 35 $\mathrm{cm}$

\subsection{Rekomendasi}

Berdasarkan permasalahan yang terjadi dan kesimpulan-kesimpulan di atas dapat disarankan sebagai bentuk rekomendasi sebagai berikut:

1. Pemerintah Kota Lhokseumawe diharapkan dapat membangun saluran drainase Sp Besi Tua-Jalan Panglima Kaom menggunakan pilihan teknologi dengan sistem luncuran.

2. Sistem luncuran yang dibuat dengan adanya perbedaan tinggi antara tiap zone dan nantinya perlu pemeliharaan secara berkala agar fungsi saluran tetap maksimal

3. Apabila pembangunan drainase ini bertahap maka direkomendasikan untuk dimulai dari Section I

4. Dengan dibangunnya drainase Sp Besi Tua-Jalan Panglima Kaom diremendasikan untuk dilakukan peningkatan jalan (overlay) minimal $5 \mathrm{~cm}$ diruas jalan tersebut. 


\section{Daftar Kepustakaan}

1. Asdak Chay, 1995, Hidrologi dan Pengelolaan Daerah Aliran Sungai, Gadjah Mada University Press, Yogyakarta

2. Soemarto, C.D., 1993, Hidrologi Teknik, Erlangga, Jakarta

3. Soewarno, 1991, Hidrologi - Pengukuran dan Pengelolaan Data Aliran Sungai (Hidrometri), Nova, Bandung.

4. Sosrodarsono S, Takeda Kensaku, 1997, Hidrologi Untuk Pengairan, PT. Pradnya Paramita, Jakarta

5. Triatmodjo Bambang, 1995, Hidaraulika, Beta Offset, Yogyakarta

6. Wesli, 2008, Drainase Perkotaan, Graha Ilmu, Yogyakarta. 